\title{
Experiments with claw models explain the function of the waving display of Ilyoplax pusilla (Brachyura: Dotillidae)
}

\author{
Daichi Izumi $^{1} \cdot$ Yoko Kawano $^{1} \cdot$ Yasuhisa Henmi $^{2}$
}

Received: 6 June 2015/ Accepted: 26 July 2015/Published online: 30 August 2015

(C) Japan Ethological Society and Springer Japan 2015

\begin{abstract}
Males of the dotillid crab, Ilyoplax pusilla, perform waving displays during the reproductive season. Unlike many fiddler crabs (genus Uca), however, the function of the waving display is unclear for this species. Experiments using waving and static claw models over short $(10 \mathrm{~cm})$ and long $(25 \mathrm{~cm})$ distances were conducted to investigate responses by wandering females to artificial waving signals. In long-distance choice experiments, presuming undirected waving to unseen females as broadcast waving, females were equally likely to approach the waving and static claw sections during the non-reproductive season, but significantly more females $(65 \%)$ chose the waving claw section during the reproductive season. In short-distance choice experiments, presuming directed courtship waving toward a particular female, there was no significant difference between the waving and static claw models during the non-reproductive season, but significantly more females $(88 \%)$ chose the waving claw during the reproductive season. These results suggest that one function of the waving display of I. pusilla is mate attraction and that waving from a short distance is more effective.
\end{abstract}

D. Izumi and Y. Kawano contributed equally to this paper and should be regarded as joint first authors.

Yasuhisa Henmi

henmi@gpo.kumamoto-u.ac.jp

1 Graduate School of Science and Technology, Kumamoto University, Kurokami, Kumamoto 860-8555, Japan

2 Aitsu Marine Station, Center for Marine Environment Studies, Kumamoto University, Matsushima, Kami-Amakusa, Kumamoto 861-6102, Japan
Keywords Claw model - Dotillid crab · Female choice . Ilyoplax pusilla $\cdot$ Signal function $\cdot$ Waving display

\section{Introduction}

A waving display, the rhythmic movement of chelipeds, is a conspicuous characteristic of ocypodid and dotillid crabs on intertidal flats. The function of the waving display has been studied mainly for fiddler crabs (genus $U c a$ ) and is regarded as a courtship and/or threat signal (Crane 1975; Christy 1987; Salmon 1987; Pope 2000). For most of these species, the waving display is performed only during the reproductive season and males perform an intensive display toward approaching females to attract then to their burrows, suggesting that the display functions as a courtship signal. However, the function of the display is unclear even within the genus Uca (Pope 2000; How et al. 2007; Muramatsu 2011).

Ilyoplax pusilla (de Haan 1835) is a small dotillid crab (ca $10 \mathrm{~mm}$ carapace width, $\mathrm{CW}$ ) that is common on intertidal sand-mud flats in Japan. Males perform waving displays during the reproductive season from April to September (Takayama 1996). Like the Uca species, the male I. pusilla sometimes performs an intensive waving display toward the female to attract her to his burrow, from a short distance. This waving display is directed toward a specific female and is performed only when the female approaches the male (directed waving; Kasatani et al. 2012). However, most of the waving by this species is a simple up-down movement of the claws, and is not directed toward any particular individual (undirected waving; Pope 2005). Moreover, in a field cage experiment with neighboring crabs of different gender, Ohata and Wada (2008) reported that I. pusilla males waved 
significantly more often when surrounded by males than when surrounded by females. They suggested that waving by this species was performed as a result of male-male competition. In other field experiments, however, Ohata and Wada (2009) indicated that undirected waving of this species functioned as a long-range courtship signal because females approached groups with a higher numbers of waving males. Thus, the function of waving display remains unclear for this species.

Detailed experimental studies of the function of the waving display have been limited by lack of a suitable method for presenting the visual signals (Burford et al. 2000). Artificial models (Reaney et al. 2008; Callander et al. 2011) and video playback (Aizawa 1998; Burford et al. 2000; McGregor 2000) of waving displays are most suitable. However, few studies of crustaceans have investigated female preference for displaying males by use of artificial models or video playback.

The males of most fiddler crabs make visual signals by broadcast waving, providing information about their location and species identity (Bradbury and Vehrencamp 1998). Broadcast waving is an undirected signal to unseen females from a relatively long distance (Pope 2005). When females approach closely enough to interact, the males change the signal to that of courtship waving toward a particular female (directed waving). The waving pattern differs between broadcast and courtship waving, and males usually increase the waving frequency and alter the nature of the signal as females approach (How et al. 2008).

In this study, female-release experiments with I. pusilla were conducted to investigate the response of wandering females to artificial waving signals (claw models). In the experiments, female choice between waving and static claws was investigated over short $(10 \mathrm{~cm})$ and long $(25 \mathrm{~cm})$ distances, presuming directed and undirected waving respectively, during reproductive and non-reproductive seasons. The simple waving display of this species enabled use of hand-operated claw models (Fig. 1).

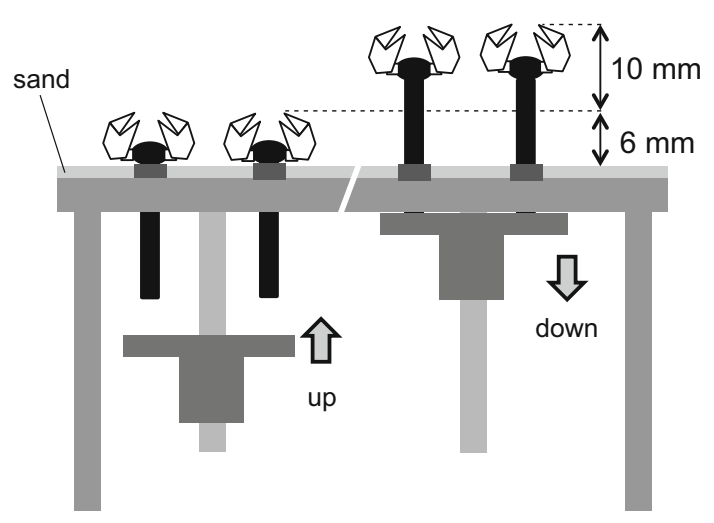

Fig. 1 Schematic illustration of the experimental apparatus
Twenty-four claw models were operated simultaneously to simulate the weak signals in the long-distance experiment, and the small body size of this species enabled arrangement of dense models. Unlike many fiddler crabs (genus $U c a$ ), the waving display of $I$. pusilla is a simple up-down movement of the claws, even in courtship waving, although the male sometimes directs vigorous waving toward a specific female when she approaches closely (Kasatani et al. 2012). Therefore, in this study, the same pattern (frequency and form) of waving display was presented for all females in the short and long-distance choice experiments. The waving display of $I$. pusilla may have a dual function, directed to rival male and receptive female conspecifics (Pope 2000). In this case, we expected that only mature females would approach the claw models during the reproductive season, and both males and females would avoid the claw models during the non-reproductive season.

\section{Methods}

\section{Study species}

Ilyoplax pusilla lives in dense, mixed-sex populations on intertidal mudflats. Each crab digs an isolated burrow and forages in the vicinity of the burrow opening during daytime low tides. It only mates underground (Wada 1981). Males tend to raise their claws simultaneously (i.e., synchronized waving; Aizawa 1998). The smallest underground mating crabs measured $5.7 \mathrm{~mm} \mathrm{CW}$ for a male and $3.9 \mathrm{~mm} \mathrm{CW}$ for a female, and the smallest ovigerous female measured $4.2 \mathrm{~mm} \mathrm{CW}$ (Henmi, personal observation).

\section{Experimental design}

The female-release experiment was conducted on a beach near Aitsu Marine Station, Kami-Amakusa, Kumamoto Prefecture, Japan $\left(32^{\circ} 31^{\prime} \mathrm{N}, 130^{\circ} 25^{\prime} \mathrm{E}\right)$ during the daytime, around spring tides during the non-reproductive (March 2011-2013) and reproductive (July and August 2011, 2013) seasons. A wooden board $(60 \times 50 \mathrm{~cm}, 5 \mathrm{~mm}$ thick $)$ was used as the arena for the experiments (Figs. 2, 3). Right and left claws of male I. pusilla were attached to the tips of nails with fast-acting adhesive to create an artificial model (Fig. 1). The claws were taken from male crabs of 6.5-7.5-mm CW (3.5-4.0-mm propodus length, PL). The claws were painted white to resemble those of actively waving males and the nails were painted black with a spray lacquer.

In the long-distance choice experiment, the board contained two $25 \times 25-\mathrm{cm}$ sections (waving and static sections) with 12 holes $(4.0 \mathrm{~mm}$ in diameter) drilled at equal 


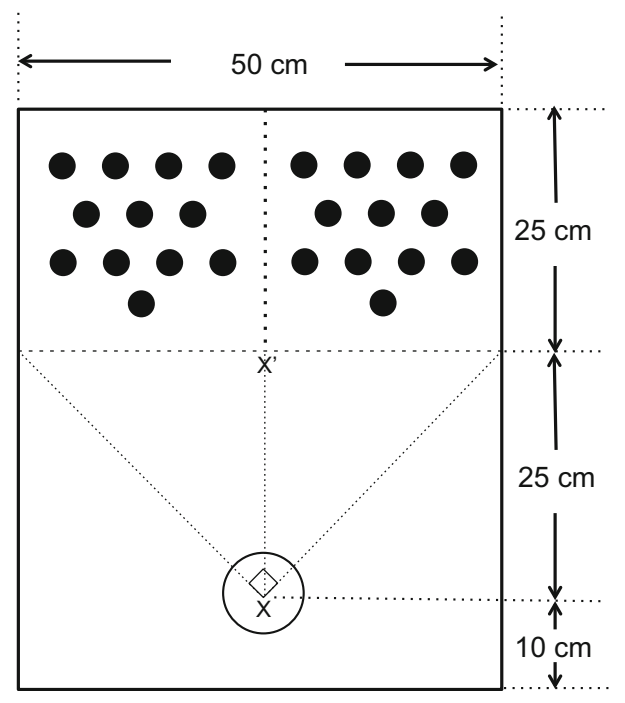

Fig. 2 Schematic illustration of the arena used in the long-distance choice experiment. The large open circle shows the position of the transparent plastic cup $(X)$ which contained the female to be tested. Filled circles indicate the positions of the claw models

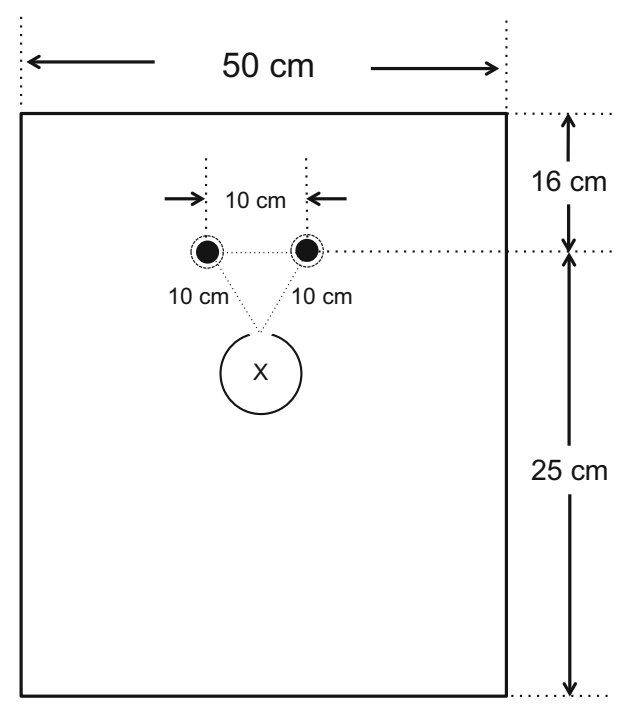

Fig. 3 Schematic illustration of the arena used in the short-distance choice experiment. The large open circle shows the position of the transparent plastic cylinder $(X)$ which contained the female to be tested. Filled circles indicate the positions of the claw models

distances from each other in each section. The board was covered with wet fine sand ( $3 \mathrm{~mm}$ thick) except for the holes. The four sides of the board were not fenced and the wandering females could move outside the board area. Each of the 24 claw models was placed in a hole. The 12 claw models in the waving section were moved simultaneously and repeatedly upward by $1 \mathrm{~cm}$ from the lowest position (once per second; $0.3 \mathrm{~s}$ up, $0.1 \mathrm{~s}$ down and $0.6 \mathrm{~s}$ pause) from the bottom of the board by hand. The waving and static sections were alternated every fifth trial.
A transparent plastic cup $(6.5 \mathrm{~cm}$ in diameter, $15 \mathrm{~cm}$ high) attached to a $60-\mathrm{cm}$-long piece of string was placed at a fixed point (X), $25 \mathrm{~cm}$ from the two sections of the arena (Fig. 2). Non-ovigerous females (6.5-7.5-mm CW), which had previously been collected from the Shirakawa River (see below), were placed individually in the cup. Ten seconds after commencing the claw model movement, the cup was lifted by pulling the string via a tripod over the board and the female was released. The section entered by the female was recorded; if the female left the board area, this also was recorded. The two lines from either end of the two sections cross at right angle (Fig. 2). In almost all cases, each crab went straight to each section or to the edge of experimental arena. Therefore, the probability of entering either section (waving or static) was estimated to be approximately $1 / 4$ and that of going outside the board to be 3/4 if the females moved randomly. Each female was used in one trial only. The time taken for the females to enter a section was recorded. If the female did not enter either section or did not leave the board area within $3 \mathrm{~min}$, the trial was cancelled. Because the purpose of the experiment was to record female choice from a long distance, data were not included if the females crossed the $\mathrm{X}-\mathrm{X}$ ' line (Fig. 2).

In the short-distance choice experiment, only two claw models were set up $10 \mathrm{~cm}$ apart (Fig. 3), and one claw model was moved repeatedly from under the board by hand. A transparent plastic cylinder $(10 \mathrm{~cm}$ in diameter, $7 \mathrm{~cm}$ high) with a rectangular exit ( $2 \mathrm{~cm}$ wide, $1 \mathrm{~cm}$ high) was placed $10 \mathrm{~cm}$ from each claw model. Non-ovigerous females were placed individually in the cylinder $10 \mathrm{~s}$ after claw model movement had started. The claw model preference of the females was noted, as was whether the females moved away from the models. If the female approached to within $1 \mathrm{~cm}$ of a claw model, we regarded her as having made a positive choice of the model. The time taken for the females to make a choice, i.e., the time between leaving the container and reaching the model, was also recorded. Most females left the cylinder rapidly, but if the female did not leave the cylinder within $3 \mathrm{~min}$ or approached the claw model via a roundabout route, the data were not included. The remaining experimental design was the same as in the long-distance choice experiment.

The females used in the experiments were captured randomly from the Shirakawa River, Kumamoto, Japan $\left(32^{\circ} 47^{\prime} \mathrm{N}, 130^{\circ} 36^{\prime} \mathrm{E}\right)$ by digging up their burrows during daytime low tides 1 or 2 days before each trial. The captured females were kept individually in plastic containers with a small quantity of sand. After the trials, the females were preserved individually in $10 \%$ formalin solution before dissection under a stereo microscope, and the ovarian weight relative to body weight (both to the nearest 
$0.1 \mathrm{mg}$ ) was recorded after the tissues had been dried at $60{ }^{\circ} \mathrm{C}$ for 2 days.

\section{Data analysis}

In the long-distance choice experiment, the ratio of females that entered either section or left the board was compared with $1: 3$ by use of a binomial test. In the short and longdistance choice experiments, the proportion of females choosing the waving or static section (model) was compared by use of a binomial test. The time taken by females to choose either section (model) was compared by use of a Mann-Whitney $U$ test. The ratio of gonad weight to body weight of females that chose either section (model) was compared by use of a Mann-Whitney $U$ test.

\section{Results}

\section{Long-distance choice experiment}

In the long-distance choice experiment, 57 of 158 females (36.1\%) entered either section during the non-reproductive season, and the ratio was significantly higher than $1 / 4$ ( $P=0.0013$, binomial test), indicating that females preferred entering either section to exiting the board (Table 1). In the choice between the waving and static sections, there was no significant difference. During the reproductive season, a proportion of females (114/160) significantly higher than $1 / 4$ entered either section $(P<0.0001)$, and significantly more females chose the waving section. The time taken did not differ significantly between the waving (18.04 $\pm 18.72 \mathrm{~s}$, mean $\pm \mathrm{SD}, N=31)$ and static sections (15.43 $\pm 12.71 \mathrm{~s}, N=25)$ during the non-reproductive season $(P=0.7490$, Mann-Whitney $U$ test $)$, nor were there any significant differences between the waving
$(10.94 \pm 9.58 \mathrm{~s}, \quad N=73) \quad$ and static sections $(8.27 \pm 7.12 \mathrm{~s}, N=39)$ during the reproductive season $(P=0.0854)$, although we failed to record the timers for three females. Relative gonad weight was not significantly different ( $P=0.9601$, Mann-Whitney $U$ test) between females that entered the waving $(3.64 \pm 3.46 \%, N=74)$ and static $(4.05 \pm 4.17 \%, N=40)$ sections. Most females were immature ( $<5 \%$ relative gonad weight; Henmi 1989) irrespective of whether they entered the waving $(55 / 74$ or $74 \%)$ or static $(28 / 40$ or $70 \%)$ sections.

\section{Short-distance choice experiment}

In the short-distance choice experiment, many females (49/ 82 or $59.8 \%$ ) chose the claw models during the non-reproductive season (Table 2), and there was no significant difference between choice of the waving and static models. During the reproductive season, almost all females (60/65 or $92.3 \%$ ) chose a claw model, and significantly more females chose the waving model over the static model. The time taken by the female to make a choice was significantly shorter $(P=0.0214$, Mann-Whitney $U$ test) for the waving model $(4.82 \pm 3.47 \mathrm{~s}, N=26)$ than for the static model $(12.31 \pm 14.74 \mathrm{~s}, N=18)$ during the non-reproductive season (no record for five females), but there was no significant difference $(P=0.3953)$ between the waving $(7.14 \pm 8.64 \mathrm{~s}, N=53)$ and static $(7.96 \pm 5.77 \mathrm{~s}, N=7)$ models during the reproductive season. Relative gonad weight was not significantly different $(P=0.3953$, MannWhitney $U$ test) between females choosing the waving $(6.64 \pm 6.11 \%, N=53)$ and static $(7.96 \pm 5.77 \%$, $N=7)$ model. Many females were immature $(<5 \%$ relative gonad weight), irrespective of whether they chose the waving $(26 / 53$ or $49 \%)$ or the static (2/7 or $29 \%)$ model.

The ratio of females choosing the waving section (model) was almost equal in the long-distance $(32 / 57$ or

Table 1 Results of the long-distance choice experiment: numbers of females that entered the waving section or the static section, or moved outside the board area during the non-reproductive and reproductive seasons

\begin{tabular}{lllrrr}
\hline & Waving claw section & Static claw section & Outside & Total & $P$ value \\
\hline Non-reproductive season & 32 & 25 & 101 & 158 & 0.4270 \\
Reproductive season & 74 & 40 & 46 & 160 & 0.0019 \\
\hline
\end{tabular}

$P$ values for exact binomial tests between the waving and static sections are given

Table 2 Results of the short-distance choice experiment: numbers of females that chose the waving model or the static model, or moved away from the models during the non-reproductive and reproductive season

\begin{tabular}{lllrrr}
\hline & Waving claw model & Static claw model & Away & Total & $P$ value \\
\hline Non-reproductive season & 27 & 22 & 33 & 82 & 0.5682 \\
Reproductive season & 53 & 7 & 5 & 65 & $<0.0001$ \\
\hline
\end{tabular}

$P$ values for exact binomial tests between the waving and static models are given 
$56 \%)$ and short-distance (27/49 or $55 \%)$ choice experiments during the non-reproductive season, but was much higher in the short-distance $(53 / 60$ or $88 \%$ ) than in the long-distance $(74 / 114$ or $65 \%)$ choice experiments during the reproductive season; however, the experimental design was different between the short and long-distance choice experiments.

\section{Discussion}

In this study, most females were attracted to waving claws from short and long distances during the reproductive season, indicating that both directed and undirected waving of I. pusilla were signals for mate attraction. Moreover, even during the non-reproductive season, significantly more females chose either a waving or static section (model). This indicates that the waving display of I. pusilla is never an expression of aggression or a threat to females. Considering Ohata and Wada $(2008,2009)$ and this study, the waving display of this species may have a dual function, serving as a threat to males and a courtship signal to females.

In the short- and long-distance choice experiments, most females that chose the waving section (model) were immature. This may be inconsistent with a function of the waving signal as a courtship display, because the opercula of most immature I. pusilla females are calcified, making it impossible to mate and oviposit (Henmi and Murai 1999). However, the waving display also indicates the position of the male's burrow, which females may run toward to avoid the risk of predation (Christy and Salmon 1991). Visits by immature females are not good for males but are temporary, and most females leave before the burrow is plugged.

In this study, significantly more females chose the waving section during the reproductive season, and the ratio was substantially higher for the short-distance choice experiment than for the long-distance choice experiment. Although the experimental design was different, it is certain that waving from a short distance is more effective, because the number of waving models (one only) was onetwelfth that in the long-distance choice experiment. At long range, a large claw size, higher waving frequency, and higher waving position may make males more conspicuous, enabling females to notice the waving group sooner. At close range, the characteristics can be discriminated more strictly and females may choose a special mate from amongst the males. Males of many fiddler crabs alter their waving pattern as females approach (How et al. 2008). Over a short distance, the conspicuity of the waving signal may not so important for female choice, but females may assess the quality of males through particular cues of courtship waving, e.g., claw size, leading wave frequency, down-swing speed, and interwave interval time for $U$. annulipes (Backwell et al. 1999) and waving height for U. perplexa (Murai et al. 2009). For I. pusilla, however, the waving pattern is almost identical irrespective of the presence or absence of females. It is possible that the waving display of this species is primitive and the conspicuity of the waving signal is important for the female choice even over a short distance. Therefore, all of the characteristics of waving (e.g., claw size, waving height) related to absolute male body size may affect female choice.

This study shows the suitability of artificial claw models for study of the function of the waving display. The small body size and simple waving display of $I$. pusilla enabled arrangement of dense waving models. Further investigations are planned to investigate the preference for claw size (Backwell and Passmore 1996), waving frequency (Backwell et al. 1999), waving height (Murai and Backwell 2006), and leading signals and synchronized waving (Backwell et al. 1999; Reaney et al. 2008) for I. pusilla by use of crab robots.

Acknowledgments We are grateful to Minoru Murai for helpful advice on this research.

\section{References}

Aizawa N (1998) Synchronous waving in an ocypodid crab, Ilyoplax pusilla: analyses of response patterns to video and real crabs. Mar Biol 131:523-532

Backwell PRY, Passmore NI (1996) Time constraints and multiple choice criteria in the sampling behaviour and mate choice of the fiddler crab, Uca annulipes. Behav Ecol Sociobiol 38:407-416

Backwell PRY, Jennions MD, Christy JH, Passmore NI (1999) Female choice in a synchronously waving fiddler crab, Uca annulipes. Ethology 105:415-421

Bradbury J, Vehrencamp SL (1998) Principles of animal communication. Sinauer, Sunderland

Burford FRL, McGregor PK, Oliveira RF (2000) Response of fiddler crabs (Uca tangeri) to video playback in the field. Acta Ethol 3:55-59

Callander S, Jennions MD, Backwell PRY (2011) Female choice over short and long distances: neighbour effects. Behav Ecol Sociobiol 65:2071-2078

Christy JH (1987) Competitive mating, mate choice and mating associations of brachyuran crabs. Bull Mar Sci 41:177-191

Christy JH, Salmon M (1991) Comparative studies of reproductive behavior in mantis shrimps and fiddler crabs. Am Zool 31:329-337

Crane J (1975) Fiddler crabs of the world Ocypodidae: genus Uca. Princeton University Press, Princeton

Henmi Y (1989) Reproductive ecology of three ocypodid crabs II. Incubation sites and egg mortality. Ecol Res 4:261-269

Henmi Y, Murai M (1999) Decalcification of vulvar operculum and mating in the ocypodid crab Ilyoplax pusilla. J Zool 247:133-137

How MJ, Zeil J, Hemmi JM (2007) Differences in context and function of two distinct waving displays in the fiddler crab, Uca perplexa (Decapoda: Ocypodidae). Behav Ecol Sociobiol 62:137-148 
How MJ, Hemmi JM, Zeil J, Peters R (2008) Claw waving display changed with receiver distance in fiddler crabs, Uca perplexa. Anim Behav 75:1015-1022

Kasatani A, Wada K, Yusa Y, Christy JH (2012) Courtship tactics by male Ilyoplax pusilla (Brachyura, Dotillidae). J Ethol 30:69-74

McGregor PK (2000) Playback experiments: design and analysis. Acta Ethol 3:3-8

Murai M, Backwell PRY (2006) A conspicuous courtship signal in the fiddler crab Uca perplexa: female choice based on display structure. Behav Ecol Sociobiol 60:736-741

Murai M, Backwell PRY, Jenniones MD (2009) The cost of reliable signaling: experimental evidence for predictable variation among males in a cost-benefit trade-off between sexual selected traits. Evolution 63:2363-2371

Muramatsu D (2011) For whom the male waves: four types of clawwaving display and their audiences in the fiddler crab, Uca lactea. J Ethol 29:3-8

Ohata M, Wada K (2008) The effect of neighbors' sex on waving frequency by male Ilyoplax pusilla (Brachyura: Dotillidae). J Crustacean Biol 28:216-219

Ohata M, Wada K (2009) Are females of Ilyoplax pusilla (Brachuyura: Dotillidae) attracted to groups having more waving male? J Ethol 27:191-194
Pope DS (2000) Testing function of fiddler crab claw waving by manipulating social context. Behav Ecol Sociobiol 47:432-437

Pope DS (2005) Waving in a crowd: fiddler crabs signal in networks. In: McGregor PK (ed) Animal communication networks. Cambridge University Press, Cambridge, pp 252-276

Reaney LT, Sims RA, Sims SWM, Jennions MD, Backwell PRY (2008) Experiments with robots explain synchronized courtship in fiddler crabs. Curr Biol 18:62-63

Salmon M (1987) On the reproductive behavior of the fiddler crab Uca thayeri, with comparisons to Uca pugilator and Uca vocans: evidence for behavioral convergence. J Crustacean Biol 7:25-44

Takayama J (1996) Population structure of Ilyoplax pusilla (Crustacea: Ocypodidae) in the Kurae River Estuary, Amakusa, Kyushu, Western Japan. Benthos Res 50:19-28

Wada K (1981) Growth, breeding, and recruitment in Scopimera globosa and Ilyoplax pusillus (Crustacea: Ocypodidae) in the estuary of Waka River, middle Japan. Pub Seto Mar Biol Lab $26: 243-259$ 